\title{
Optimal Pricing of Mass Customized Products for Logistics Outsourcing
}

\author{
Peng Jiang, Yi-Chung Hu \& Ghi-Feng Yen \\ Department of Business Administration, Chung Yuan Christian University, Chung-Li, Taiwan
}

\begin{abstract}
Recently, with increasingly fierce market competition, manufacturers have to introduce mass customization production. Under the guidance of the core competence theory, many manufacturers will outsource their logistics activities to a professional third-party logistics companies which are good at supply chain management. This paper constructs an objective function on profit maximization of manufacturer, so that it discusses how the costs of third-party logistics service influence the income of manufacturers. Also, the article determines the best price which is expected to maximize the benefits of manufacturers.
\end{abstract}

KEYWORDS: Logistics outsourcing; Third-party logistics; Mass customization; Optimal Pricing

\section{INSTRUCTIONS}

Economic globalization and the accelerating process of economic integration promote industrial restructuring in the world, and the growing influences of multinational companies also promote the scientific and technological advances in the global scope. Customer demand has led to an increasingly personalized shorten product life cycle. Therefore, in order to balance the market structure, changes of customer demand and manufacturers core competitiveness, mass customization production increasingly apparent. Due to its ability to fully meet diverse final customers demand with individuation, manufacturers will get higher profits.

In practice, the manufacturers that take application of mass customization could not obtain the expected profit, because the factors which affect their success are so much, for example, the level of $\mathrm{R} \& \mathrm{D}$ of new products, production processes and technology, organizational structure, logistics and other support activities. It is proved that logistics is a key factor which affects the achievement of mass customization production (Li et al., 2014). Price of product is bound to contain certain logistics costs because of outsourcing logistics. And the level of prices has a direct impact on the level of manufacturer expected revenue through demand effector mechanisms, so exploring the optimal price of mass customized products is very meaningful.

\section{LITERATURE REVIEW}

Toffler (1970) predicted that mass customization will gradually be taken seriously in future production services. But the theory on mass customization was first proposed by Davis (1987), his book--Future Perfect points out the business or organization can combine their own competitive advantage to produce goods and services on a large scale driven by customers' demand. In the "Mass Customization: The New Frontier in Business competition" written by Pine (1993) noted that the core of mass customization is diversity and variety of customized products which has a sharp increase without a corresponding increase in costs. And its biggest advantage is to provide a strategic advantage and economic value, so that Mass Customization (MC) is widely recognized around the world.

In recent years, researches on MC have been focused on problems about customized production. $\mathrm{Xu}$ et al. (2001) and $\mathrm{Xu}$ et al. (2002) proposed the best way to achieve MC production is "to reduce the amount of customization in the production process, and maximize the use of common parts and processes so as to reduce the custom components and custom parts and services caused by the changes in order to achieve unity of large quantities of two modes of production and customization". Dan (2004) put forward to five MC technologies which can achieve the demands including diversity, time and cost, namely product family, product platform design, advanced manufacturing technology, ecommerce, flexible production management and agile supply chain. 
In academia, there are some mainly representative views about the researches on the relationship between logistics and mass customization, as follows.

Gooley (1998) considers logistics activities penetrate the entire supply chain operations, including raw materials and parts suppliers, assembly manufacturers, distributors, retailers and end customers. Logistics activities will link each node together throughout the supply chain. Zipkin (2001) proposed that mass customization is restricted from four levels, namely flexible production technology, management system to transmit real-time information on customers' demand, improved distribution system and reasonable costs of customized services.

Partanen and Haapasalo (2004) put forward to four functional modules to support mass customization, new product development module, production schedule control module, marketing module and logistics and distribution module included.

Furthermore, Shao et al. (2001) and Luo (2002) considered that low level of logistics management will restrict the development of mass customization.

In summary, for manufacturers, if there is not a high level of logistics operations, raw materials can not enter the production line according to plan, and thus it will lead goods delay in processing. What is worse, those will prevent the realization of mass customization production. So logistics is a key to achieve mass customization production. However, there are still few studies on the mechanism of logistics impact on mass customization.

\section{RESEARCH METHOD}

\subsection{Description of the problem}

Suppose a manufacturer named A implements mass customization production, and A's logistics activities are outsourced to a professional third-party logistics enterprise B. Because of the advantages of logistics outsourcing are enhancing the core competitiveness and improving customer service levels of manufacturers, this article constructs an "Expected Revenue Maximization" as the research model. In order to facilitate the research, this paper selects a simple supply chain which consists of one supplier, one 3PL ( ${ }^{\text {rd }}$ Party Logistics) and some consumers. Under the premise of that A and B can share the information completely, the simple supply chain is shown as Fig.1.

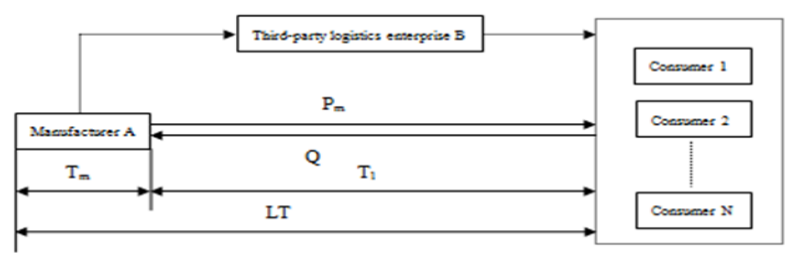

Fig.1. Supply Chain Structure

\subsection{Assumptions}

(1)Manufacturer has sufficient production capacity and there are no process reengineering and other circumstances. Production time is not affected by the quantity of customers' order.

(2)The relationship between actual demand rate and commodity price of the product is inversely proportional in market.

(3)The relationship between actual demand rate of the product and lead time is proportional in market.

(4)The relationship between liquidated damages and delay is proportional in supply chain.

(5)The goods will be in transportation after production. And there is no inventory.

(6)When delivery is delayed, liable party should pay a certain amount of fines to the injured party. But it does not affect the cooperation.

(7) Mass customization production is applied.

\subsection{Notations}

$\boldsymbol{H}_{\boldsymbol{m}} \quad$ Manufacturer's expected revenue

$\boldsymbol{P}_{\boldsymbol{m}}$ Commodity price

$\boldsymbol{P}_{\boldsymbol{l}} \quad$ Price of logistics services

$\boldsymbol{C}_{\boldsymbol{m}} \quad$ Unit cost of product

$\boldsymbol{C}_{\boldsymbol{l}} \quad$ Unit cost of logistics services

$\boldsymbol{F}_{\boldsymbol{m}}$ Liquidated damages that manufacturer should pay to consumer due to goods delay

$\boldsymbol{F}_{\boldsymbol{l}} \quad$ Liquidated damages that 3PL should pay to the manufacturer due to goods delay

D Market demand rate of commodities

$\boldsymbol{a}$ The largest commodity demand rate

$\boldsymbol{b}_{\boldsymbol{1}} \quad$ Price elasticity of market demand rate

$\boldsymbol{b}_{2}$ Response time elasticity of market demand rate

$\boldsymbol{T}_{l} \quad$ Operating time of 3PL, that is the time of goods transport from producers to consumers

$\boldsymbol{T}_{\boldsymbol{m}} \quad$ Product time of unit production

$\boldsymbol{L T}$ Lead Time, $\boldsymbol{L T}=\boldsymbol{T}_{l}+\boldsymbol{T}_{\boldsymbol{m}}$

$\boldsymbol{t}$ Actual operation time of 3PL, so that $\boldsymbol{F}(\boldsymbol{t})$ for the distribution function and $\boldsymbol{f}(\boldsymbol{t})$ for the density function, thus the average time for logistics operations is $1 / \lambda$.

\subsection{Model Construction}

According to description of the problem, Fig. 1 shows that market demand of manufacturer is

$$
D=a-b_{1} P_{m}-b_{2} L T\left(\mathrm{a} \geq 0, \mathrm{~b}_{1} \geq 0, b_{2} \geq 0\right)
$$

where $L T=T_{l}+T_{m}$, so the total order amount of the market based on supply chain above is

$Q=D\left(P_{m}, T_{l}\right)$

Supposes $t$ obeys the exponential distribution parameter $\lambda$, the average time for logistics operations is $1 / \lambda$, and $f(t)$ is the density function, therefore the distribution function is 
$\mathrm{F}(\mathrm{t})=1-e^{-\lambda t}(\lambda \geq 0)$

So the expected revenue function of manufacturer is

$$
\mathrm{H}_{\mathrm{m}}=\left[P_{m}-C_{m}-P_{l}-F_{m} \int_{T_{l}}^{\infty}\left(t-T_{l}\right) f(t) d t+F_{l} \int_{T_{l}}^{\infty}\left(t-T_{l}\right) f(t) d t\right] D
$$

Where $\boldsymbol{P}_{\boldsymbol{m}}$ means commodity price, $\boldsymbol{C}_{\boldsymbol{m}}$ means unit cost of product, $\boldsymbol{P}_{\boldsymbol{l}}$ means the price of logistics services, and $F_{m} \int_{T_{l}}^{\infty}\left(t-T_{l}\right) f(t) d t$ shows liquidated damages that manufacturer should pay to consumer due to goods delay, and $F_{l} \int_{T_{l}}^{\infty}\left(t-T_{l}\right) f(t) d t$ shows liquidated damages that 3PL should pay to the manufacturer due to goods delay, D represents final order quantity in the consumer market.

\subsection{Model Analysis}

The description of the problem shows that manufacturer A and 3PL B can achieve real-time sharing of the information based on the supply chain above-mentioned. When the consumers make orders to manufacturer A, 3PL B can give a promise about the services according to the actual needs of customers, including the price $\boldsymbol{P}_{\boldsymbol{l}}$ and operating time $\boldsymbol{T}_{\boldsymbol{l}}$ of logistics services. After receiving the reply from 3PL B, manufacturer A can report the commodity price $\boldsymbol{P}_{\boldsymbol{m}}$ and lead time to consumers according to production capacity, production time and so on. Therefore, service price and operating time of 3PL should be decided first, in order to achieve maximum expected revenue of manufacturer. Manufacturer expected revenue function is shown as Eqs. (4).

Eqs. (1) is substituted into Eqs. (4).

$$
\begin{aligned}
& \mathrm{H}_{\mathrm{m}}=\left[P_{m}-C_{m}-P_{l}-F_{m} \int_{T_{l}}^{\infty}\left(t-T_{l}\right) f(t) d t+F_{l} \int_{T_{l}}^{\infty}\left(t-T_{l}\right) f(t) d t\right] \\
& {\left[a-b_{1} P_{m}-b_{2}\left(T_{l}+T_{m}\right)\right]}
\end{aligned}
$$

For the first-order derivative formula of $\boldsymbol{P}_{\boldsymbol{m}}$,

$$
\begin{aligned}
& \frac{\partial H_{m}}{\partial P_{m}}=\left(a-b_{2} T_{l}-b_{2} T_{m}-2 b_{1} P_{m}\right) \\
& +b_{1}\left[P_{m}+C_{l}+\left(F_{m}-F_{l}\right) \int_{T_{l}}^{\infty}\left(t-T_{m}\right) f(t) d t\right]
\end{aligned}
$$

Since $\boldsymbol{P}_{\boldsymbol{m}}$ for commodity price of manufacturers, so the domain of the first-order partial derivative above is $(0,+\infty)$. Let $P_{m_{1}}<P_{m_{2}}$ and $P_{m_{1}}, P_{m_{2}} \in(0,+\infty)$, there is

$$
\frac{\partial H_{m_{1}}}{\partial P_{m_{1}}}-\frac{\partial H_{m_{2}}}{\partial P_{m_{2}}}>0
$$

So this first-order partial derivative in its definition domain is monotonically decreasing.

For the second-order derivative formula of $\boldsymbol{P}_{\boldsymbol{m}}$,

$$
\frac{\partial^{2} H_{m}}{\partial P_{m}^{2}}=-2 b_{1}<0
$$

From the equation above, in the case of given logistics services price $\boldsymbol{P}_{l}$ and operating time $\boldsymbol{T}_{l}$, manufacturers A's expected revenue is a concave function on commodity prices $H_{m}$. So there is a maximum in the domain $(0,+\infty)$. Let $\frac{\partial H_{m}}{\partial P_{m}}=\mathbf{o}$, there is

$$
\begin{aligned}
& P_{m}{ }^{*}=\frac{a-b_{2} T_{l}-b_{2} T_{m}}{-2 b_{1}} \\
& +\frac{1}{2}\left[P_{m}+C_{l}+\left(F_{m}-F_{l}\right) \int_{T_{l}}^{\infty}\left(t-T_{m}\right) f(t) d t\right]
\end{aligned}
$$

So $\boldsymbol{P}_{\boldsymbol{m}}{ }^{*}$ is the optimal price which maximize the benefits of the manufacturer's expectation.

\subsection{Summary}

From the analysis above, it is shown that for a given services price $\left(\boldsymbol{P}_{l}\right)$ and service time $\left(\boldsymbol{T}_{l}\right)$ of $3 \mathrm{PL}$ $\mathrm{B}$, there is an optimal price that can make the biggest benefits to manufacturer A.

Moreover, this conclusion also shows that manufacturer's profitability is affected by 3PL, in which the service price $\left(\boldsymbol{P}_{l}\right)$ and service time $\left(\boldsymbol{T}_{l}\right)$ of 3PL are the important factors that directly affect manufacturer's final earnings.

\section{MANAGEMENT IMPLICATIONS}

Due to profitability, manufacturers have to adopt mass customization production, and their profit will be largely influenced by its cooperative logistics companies. As a result, operational performance and capabilities of these 3PLs will directly influence the production and sales of manufacturers.

\subsection{Improving the ability of service in $3 P L s$}

To improve the ability of service in 3PLs, the first thing they should do is to increase the construction of logistics information systems and infrastructure of 3PL. According to the development trend of the logistics industry, those companies, which not only have mass logistics facilities and perfect network but also have a strong ability of design, is able to integrate IT and implementation capacity and then provide a one-stop integrated logistics solutions. Logistics infrastructure is the premise and foundation to ensure the service time of logistics.

Secondly, while the 3PLs provide basic logistic services, they should continue to segment the market according to market demand, expand the scope of business and develop value-added logistics services. For example, they can provide services in processing, distribution, freight forwarders and so on. These companies should strive to achieve the target, which includes such integrated logistics services as providing solutions of supply chain and building information platform of logistics. They are required to meet individual needs with professional 
services and provide one-stop service for client companies.

\subsection{Improving the ability of market maintenance and development in 3PLs}

3PLs should do fully research and analysis of the current situation and needs of client companies. The purpose of producing in manufacturing companies, which implement mass customization production, is to directly meet the needs of consumers. Therefore, 3PLs should clarify its position and role in the manufacturer's supply chain, analyze the needs of client companies, and ensure that logistics services should be consistent with direction of the business, situations of ability and structure of resources in client companies.

In addition, 3PLs should always pay attention to motivations that client companies outsource the logistics service and to priority interest. At the same time, they shall show their strong abilities in logistics services, win the trust of customers and finally make strategic alliances and maintain good relations.

\subsection{Improving the speed of reaction in $3 P L s$}

Intensive market competition result to the fact that consumers have an increasingly personalized demand of products made by manufacturers. Also with shorter life-cycles of products, client companies react more frequently to the changes in the demand of logistics service. So the 3PLcompanies should have relatively strong ability of reaction. When are required to change the needs by the client companies, they can integrate existing resources to provide the needed services or products in time. This is the prerequisite and guarantee for logistics companies that whether they can occupy a favorable position in the market competition.

\subsection{Strengthening the cost control in 3PLs}

From the conclusion of this paper, it is obvious that the profits of manufacturers are influenced by the service price that logistics companies charge. Thus, in order to maintain the alliance with manufacturing companies, the 3PLs must face the profit of client companies. In other words, they had better reduce the cost of logistics operations and transfer the profit distribution space to client companies. So reducing the cost of logistics operations is the key issue of the 3PLs. Due to the fact that logistics service are based on the transactions between the 3PLs and client companies, the 3PLs should not only fully consider the expense which the client companies are willing to pay to accept the logistics service, but also consider the dual nature in benefits of logistics services generated by logistics companies. That is to say, the profits made by logistics companies are part of profits of client companies.

In addition, 3PLs should base on a systematic point of view to make cost and benefit analysis for client companies, provide operating suggestions on how to reduce costs and improve customer satisfaction with the 3PLs. Meanwhile, 3PLs should strengthen internal management and control costs of logistics operations.

\section{REFERENCES}

[1] Dan, B. Mass Customization - to Build Core Competitiveness of Business in the 21 ${ }^{\text {st }}$ Century. 2004. Beijing: Science Press.

[2] Davis, S.M. 1987. Future Perfect. Boston: AddisonWesley.

[3] Gooley, T.B. 1998. Mass customization: How logistics makes it happen. Logistics Management and Distribution Report. 37(4):49-53.

[4] Li, Z.Z. Wang, J.Z. Wang, S.Y. Wang, Y. Yang, J.L. 2014. Customization-massing: A new perspective on mass customization. Modern Manufacturing Engineering. 24 (5): 136-140.

[5] Luo, R.R. 2002. Be careful: Trap of mass customization. Vitality of Enterprises. 16 (5):44-45.

[6] Partanen, J. Haapasalo, H. 2004. Fast production for order fulfillment: Implementing mass customization in electronics industry. International Journal of Production Economics. 90(2):213-222.

[7] Pine II, J. 1992. Mass Customization: The New Frontier in Business Competition. Boston: Harvard Business School.

[8] Shao, X.F. Huang, P.Q. Ji, J.H. 2001. Research on Mass Customization Mode. Industrial Engineering and Management. 48(2):13-17.

[9] Toffler, A. 1970. Future Shock. Bantam: Reissue.

[10] Xu, F.Y. Li, M. Wang, H.S. Gu, X.J. 2001. Research on system optimization methods to implement of mass customization. Computer Integrated Manufacturing Systems. 38(6):45-48.

[11] Xu, F.Y. Li, M. Wang, H.S. Gu, X.J. Han, L. Xiang Y. H. 2002. Basic ideas of implementation in mass customization and integration time and space optimization model. Journal of Industrial Engineering and Management. 39(6):50-52.

[12] Zipkin, P. 2001. The limits of mass customization. MIT Sloan Management Review. Spring: 81-87.

\section{ABOUT THE AUTHORS}

Peng Jiang, a PhD candidate in Dept. of Business Administration, Chung Yuan Christian University, Research fields: Logistics and Supply Chain Management. Dr. Yi-Chung $\mathrm{Hu}$, a professor in Dept. of Business Administration, Chung Yuan Christian University. Research fields: Multi-Criteria Decision Making, Data Mining, Electronic commerce, Soft computing. Dr. Ghi-Feng Yen, a Professor in Dept. of Business Administration, Chung Yuan Christian University. Research fields: Supply Chain Management, Corporate Governance, Leadership and Followership, Strategic Management, Economic Order Quantity with Trade Credit 